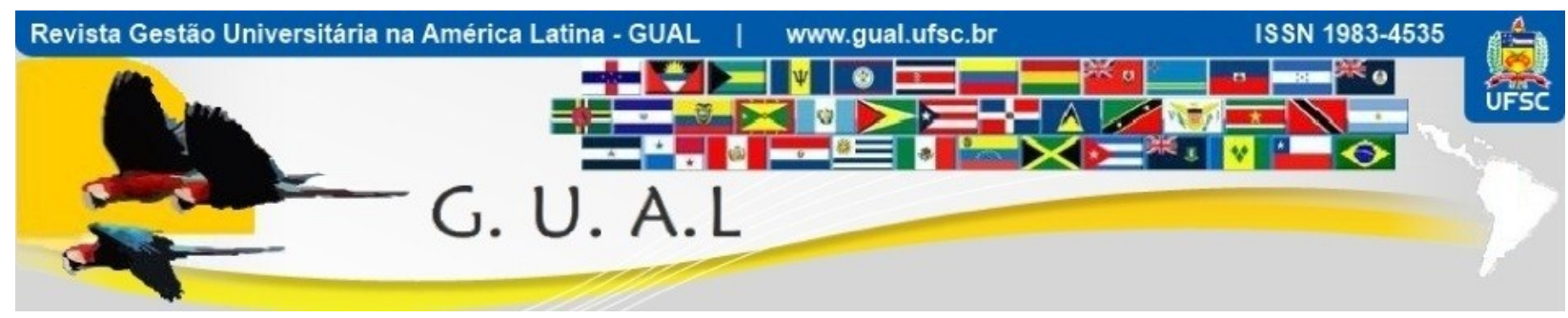

DOI: http://dx.doi.org/10.5007/1983-4535.2012v5n4p141

\title{
MATERIAL DIDÁTICO EM EDUCAÇÃO A DISTÂNCIA: FRAGMENTAÇÃO DA DOCÊNCIA OU AUTORIA
}

\author{
DIDACTIC MATERIALS IN DISTANCE EDUCATION: TEACHING \\ FRAGMENTATION OR AUTHORSHIP
}

Eliane Medeiros Borges, Doutora Universidade Federal de Juiz de Fora - UFJF mborges.eliane@gmail.com

Diovana Paula de Jesus, Graduanda Universidade Federal de Juiz de Fora - UFJF diovana_paulaj@yahoo.com.br

Danilo Oliveira Fonseca, Graduando Universidade Federal de Juiz de Fora - UFJF danilo.oliveirajf@gmail.com

Recebido em 16/novembro/2012

Aprovado em 07/dezembro/2012

Sistema de Avaliação: Double Blind Review

Esta obra está sob uma Licença Creative Commons Atribuição-Uso. 


\title{
RESUMO
}

O artigo apresentado visa traçar uma compreensão acerca da produção de materiais didáticos para cursos de Educação a Distância $(\mathrm{EaD})$. A partir da percepção de que o material didático é parte importante da maioria dos projetos da modalidade, procuramos tomar conhecimento da concepção de educação subjacente a esta produção. Busca-se também investigar modelos que tendem a prevalecer nas práticas contemporâneas de EaD no país. A investigação, ainda em curso, aborda duas possibilidades de construção de material didático para EaD: a primeira, que apregoa uma feitura industrial e segmentada, com ênfase na transmissão de conhecimento e informação; e a segunda possibilidade, supondo uma realização mais artesanal e dinâmica, tendo como base a autoria e autonomia do professor nos materiais apresentados. O estudo se concentrou em dois cursos específicos de EaD da UFJF, pertencentes ao modelo da Universidade Aberta do Brasil (UAB) com o intuito de comparar dois sistemas de curso em pleno funcionamento. Foram aplicados questionários aos professores de ambos os cursos, e entrevistas com os professores do curso que tinha material didático pré-produzido. Os resultados apontam para o esforço de autoria do professor, mesmo quando impelido à utilização de material didático elaborado sem a sua participação.

Palavras-chave: Material didático. Educação a distancia. Tecnicismo na EaD.

\begin{abstract}
The article aims to present an understanding of the production of teaching materials for courses in Distance Education (DE). From the perception that the teaching material is an important part of most projects of this practice, we aim to perceive the concept of education underlying this production. We also search to investigate models that tend to prevail in contemporary practices of distance education in Brazil. The investigation, still in progress, discusses two possible construction of educational material for distance education: the first, industrially and fragmented built, with emphasis on the transmission of knowledge and information, and the second possibility, assuming an accomplishment in a more artisanal and dynamic way based on teacher autonomy and authorship in the materials presented. The study focused on two specific courses DL UFJF belonging to the model of the Open University of Brazil (UAB) in order to compare two systems course in full operation. Questionnaires were administered to teachers of both courses, and interviews with teachers of the course that has pre-produced learning material. The results point to the effort made by professors to be the author of their disciplines, even when pushed to the use of educational materials developed without their participation.
\end{abstract}

Keywords: Educational material. Distance education. Technicism in Distance education. 


\section{INTRODUÇÃO}

O cenário da Educação a Distancia $(\mathrm{EaD})$ no país vem se consolidando há algum tempo como modalidade aceita e reconhecida de educação. Deixando de lado uma imagem de educação ligada à morosidade e a certa ineficiência, a EaD vem com uma nova roupagem à medida que se associa às Tecnologias de Interação e Comunicação (as TIC's) como instrumento e meio de ação trazendo, deste modo, uma nova dinâmica à forma de se estudar e aprender à distância. Especificamente no Brasil, nos últimos tempos, a EaD está aparecendo como modalidade bastante recorrida contribuindo, em princípio, de forma decisiva para a democratização do ensino superior no país.

Para compreender a influência de tais modelos econômicos e de gestão no campo da educação, e da $\mathrm{EaD}$ em particular, é preciso lembrar que o grande desenvolvimento econômico do período capitalista de pós-guerra se caracterizou pela crescente penetração dos novos modelos teóricos e das práticas da economia sobre os outros campos da vida social. (BELLONI, 2009, p. 13)

É nesse panorama que se insere a Educação a Distância. Por decisão de uma política pública, ela vem crescendo e se desenvolvendo no país de maneira bastante rápida e intensa. Segundo o Ministério da Educação ${ }^{\mathrm{i}}$ em 2011 a Educação a distância deveria chegar a um total de um milhão de alunos conveniados ao ensino superior, dentro de um universo de cinco milhões de alunos vinculados ao ensino superior publico brasileiro. Belloni (2009) também descreve esse movimento da $\mathrm{EaD}$, mas de uma forma que ressalta o quanto a mesma está se inserindo no cotidiano do mundo acadêmico sem ser pensada e refletida no mesmo grau.

O desenvolvimento da pesquisa trouxe, porém, algumas considerações fundamentais capazes de indicar o que seria realmente relevante no que diz respeito à construção de um modelo de ação de educação a distância. Os estudos teóricos nos mostravam o quão grande, interessante e carente de estudos estava o campo de educação a distância. Ao mesmo tempo, mostrava também as deficiências que o modo de fazer ensino a distância atual continha, assim como delimitava firmemente dois modelos bastante diferentes entre si na modalidade. Como afirma Belloni:

Pode-se dizer que desde os anos 80, duas manifestações teóricas predominantes se afrontam ou coexistem no campo da educação em geral e da EaD em particular: de um lado o estilo fordista de educação de massa e do outro uma proposta de educação mais aberta e flexível, supostamente mais adequada às novas exigências sociais. Essas duas tendências 
coexistiram confortavelmente, mas a partir da década de noventa (...) a lógica industrialista começou a perder terreno, sendo percebida como uma ameaça as "qualidades menos tecnocratas e mais humanistas" vislumbradas como possíveis a partir de teorias da pós-modernidade e de modelos pósfordistas e de organização industrial. A maioria dos estudiosos concorda que os objetivos e as estratégias da educação a distância estão sendo (ou devem ser) redefinidos em função de análises a criticas orientadas pelos paradigmas pós-modernos e desconstrucionistas. Essa redefinição se dá em direção a abertura e afasta-se do "behaviorismo de massa". (2009, p.11)

Portanto, passamos a olhar de forma mais atenta a essa diferença de modelos de $\mathrm{EaD}$, que refletem distintos modos de lidar com as diferentes mídias, com as interações entre os sujeitos da aprendizagem, com a abordagem dos conteúdos. O que inicialmente suspeitávamos se confirmou ao longo de nossa pesquisa: que essa diferença de modelos se traduzia em diferente uso e construção do respectivo material didático. A partir do material produzido e utilizado nos cursos a distância é possível identificar em qual modelo o curso é fundamentado, como ele se comporta nos pontos anteriormente descritos. Deste modo, percebemos que estudar o material didático pode abranger muito mais do que o estudo de configurações específicas de conteúdos e formas.

Pensamos que o material didático é importante para se compreender a educação a distância porque o mesmo se posiciona como peça chave do modelo adotado. No material se concentram a proposta do curso, sua base e orientação pedagógica, o papel dos tutores, dos alunos, enfim, todas essas características estão contidas na configuração do material e podem ser percebidas se nos dedicarmos mais a esse ponto. É a partir dele e do manuseio com ele que os professores delimitam suas ações - mais ou menos intensas e atuantes, e, consequentemente, delimitam as respostas e interações que os alunos devem fazer com o contexto. Os recursos contidos nos materiais - ou a falta deles - expressam a contextualização dos mesmos com as mídias digitais. A forma com que o material é construído - levando em conta a redução, simplificação e o modo com que expõe o conteúdo - se reflete na forma com que tal material será absorvido e entendido.

No Brasil instalou-se a prática de fornecer ao aluno apenas uma 'apostila' ou resumo dos pontos principais da matéria, às vezes com apenas 50 páginas contendo 'pedaços de conhecimento' (extraído de diferentes livros) intercalados para constituir uma 'nova' publicação (frequentemente sem citação das fontes originais, nem o pagamento de direitos autorais para uso comercial). Essa redução do conteúdo apresentado ao aluno representa, evidentemente, uma diminuição de seu conhecimento e de seu preparo profissional. (LITTO, 2009, p. 18). 


\section{METODOLOGIA}

A proposta do artigo aqui apresentado é, portanto, analisar uma oposição entre modos de construir um material didático e sistematizar um curso, usando como base de estudo a forma desses cursos e as possíveis implicações do formato com sua didática e metodologia. Para que essa proposta se efetivasse, o estudo se concentrou em dois cursos específicos de EaD da UFJF, pertencentes ao modelo da Universidade Aberta do Brasil (UAB) - os cursos que chamaremos de A e B, com o intuito de comparar os dois sistemas de curso em pleno funcionamento, formando turmas e se desenvolvendo pedagogicamente.

A escolha dos cursos acima apontados foi baseada na possibilidade do estudo da seleção e produção de material didático impresso (apostila, livros ou textos selecionados) em cursos de EaD com diretrizes e projetos pedagógicos diferenciados: um material com ênfase em uma produção planejada e prévia (curso A) e outro ancorado na construção e desenvolvimento ao longo do curso (curso B).

Uma das necessidades subjacentes ao estudo apresentado estava na utilização de um mecanismo capaz de obter avaliação dos principais sujeitos dos cursos em questão (professores e alunos), sobre os conteúdos, formas e usos dos materiais. Para isso foi proposto o desenvolvimento de dois instrumentos de coleta de dados: a aplicação de questionários e entrevistas. A proposta dos questionários era de ser aplicada aos professores dos cursos responsáveis por desenvolver e selecionar o material utilizado - para obter um panorama geral do entendimento desses sujeitos. Já a entrevista teria o intuito de ser aplicada somente a alguns professores, objetivando um entendimento mais específico e, ao mesmo tempo, mais profundo da compreensão desse processo produtivo.

A partir de nossa compreensão de que são os sujeitos que produzem os cursos que melhor poderiam nos explicar sobre eles, fomos buscar em professores dos cursos as principais informações sobre o efetivo uso do material didático nos cursos de EaD. Com esta finalidade realizamos um pequeno número de questionários com os professores de ambos os cursos, e entrevistas com os professores do curso que tinha material didático pré-produzido, ou seja, o curso A.

\subsection{QUESTIONÁRIOS E PRIMEIROS DADOS}

O questionário foi o primeiro recurso metodológico produzido, aplicado aos professores que tiveram experiência em lecionar o ensino a distância dos dois cursos 
analisados. Para a formulação das questões propostas, as especificidades de cada curso foram levadas em conta, e, por isso, não foi aplicado o mesmo questionário aos dois cursos. Ao curso que não apresentava o uso do material didático impresso pré-elaborado, foram suprimidas as questões que diziam respeito á satisfação dos professores com o material didático recebido e as características de tal material.

\subsection{ENTREVISTAS}

O outro recurso utilizado foi o de entrevistas com professores do Curso A, a fim de traçar um quadro mais descritivo do movimento e dinâmica do curso, assim como as bases que o regem. Estes sujeitos foram selecionados de forma que apresentassem um perfil diferenciado e que, juntos, pudessem formar um panorama mais completo de como diferentes perfis de professores se comportam em tal curso.

\subsection{A AVALIAÇÃO DO CURSO COMO FONTE DE DADOS}

Utilizou-se, para comparação com os resultados obtidos dos instrumentos anteriores, os questionários realizados, pela mesma equipe desta pesquisa, de avaliação do curso $\mathrm{B}$, junto aos alunos do curso, a cada semestre. O questionário utilizado, de 75 questões, inclui perguntas sobre a percepção que os alunos têm do material didático e das interações com professores e tutores. A partir dos estudos da pesquisa aqui sendo relatada, um novo olhar foi dirigido às questões propostas, de maneira a comparar seus resultados com as reflexões teóricas e novos dados obtidos.

\section{RESULTADOS E DISCUSSÕES}

De início, foi traçado um panorama geral do uso dos materiais, produzidos e apresentados nos respectivos cursos. O curso A tem seu material impresso em livros-texto, com indicações de leitura e exercícios. Tal material é produzido de maneira centralizada pela UAB, sendo, portanto, idêntico em todos os cursos no país, independentemente de diferenças locais.

Já o curso de B tem claramente outras perspectivas no que se refere à construção de um material de apoio para os estudantes. Não possui um material com um formato prédefinido, que vai passando de ano para ano, de disciplina para disciplina, assim como não possui nem distribui material impresso a seus alunos. De modo específico, o curso tem seu 
material baseado no uso das mídias tecnológicas e de textos que podem ser disponibilizados via sites da internet, downloads ou pela própria plataforma do curso. A proposta desse modelo está em uma interação mais intensa no Ambiente Virtual de Aprendizagem(AVA), interação entre os próprios alunos, assim como entre os tutores e alunos. Assim, o conhecimento seria produzido conjuntamente, mediado pelos tutores - e intermediado pelo material produzido pelo professor, de modo individual para cada disciplina e necessidade da turma.

No que se refere à análise desses materiais didáticos é possível fazer uma consideração quanto ao modo com que os mesmos são disponibilizados ao aluno. O primeiro, de forma impressa, chega às mãos do aluno e possibilita aos mesmos uma segurança no que diz respeito a ter um auxilio sempre perto fisicamente, que ofereça uma resposta quando o aluno não tiver para quem apelar em uma dúvida. Disponibiliza esse material de forma apostilada, de modo que possibilite o uso contínuo e frequente do material para a disciplina em diferentes semestres.

Já o curso de Pedagogia a distância propõe algo que se aproxime mais da concepção de material de estudo do ensino tradicional presencial, como ele acontece hoje nas universidades. Concentra-se mais em materiais como livros, capítulos de livros, artigos que são disponibilizados na internet e discussão nas plataformas de estudos. Tudo isso está no intuito de aproximar a dinâmica e a didática da EaD ao ensino regular e afastar a Educação a Distância de possíveis práticas de uma educação simplista.

O questionário acima mencionado como recurso metodológico possibilitou a retirada de alguns dados quantitativos no que se refere a uso do material didático pelos docentes de $\mathrm{EaD}$, especificamente no que diz respeito ao material didático impresso utilizado pelos cursos. No curso A, quando perguntado aos professores acerca do material nos quesitos de pertinência do conteúdo, quantidade de atividades propostas e do uso de materiais complementares as respostas foram as seguintes:

Tabela 1 Quanto ao conteúdo do material didático utilizado

\begin{tabular}{ccc}
\hline & Freqüência & Percentual \\
\hline Muito pertinente & 2 & $25 \%$ \\
Pertinente & 3 & $37,5 \%$ \\
Pouco pertinente & 3 & $37,5 \%$ \\
Total & 8 & $100 \%$ \\
\hline
\end{tabular}

Fonte: Elaborado pelos Autores 


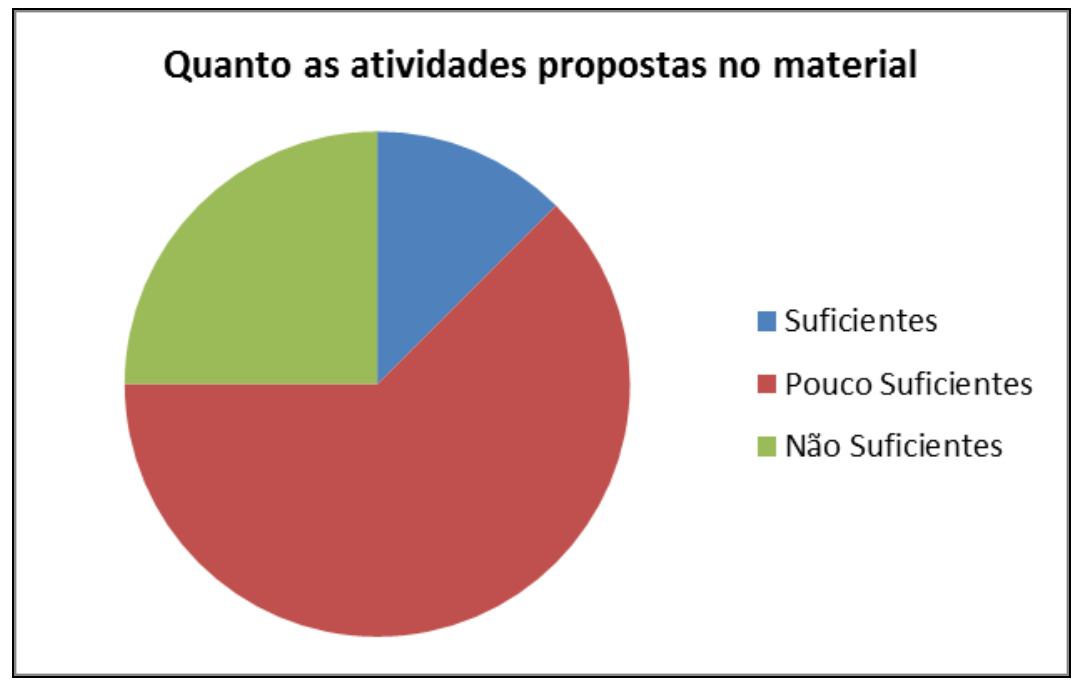

Figura 1 Quanto às atividades propostas no material Fonte: Elaborado pelos Autores

Tabela 2 Se utiliza material impresso

\begin{tabular}{lcc}
\hline & Freqüência & Percentual \\
\hline Integralmente & 3 & $37,5 \%$ \\
Em parte & 5 & $62,5 \%$ \\
Total & 8 & $100 \%$ \\
\hline
\end{tabular}

Fonte: Elaborado pelos Autores

Tabela 3 Se utiliza material complementar:

\begin{tabular}{lcc}
\hline & Freqüência & Percentual \\
\hline Muita frequência & 7 & 87,5 \\
Pouca freqüência & 1 & 12,5 \\
Nenhum uso & - & - \\
Total & 8 & $100 \%$ \\
\hline
\end{tabular}

Fonte: Elaborado pelos Autores

Não houve uma concordância absoluta no que diz respeito à pertinência do conteúdo do material didático com a matéria lecionada, questão que remete a um ponto também pautado nos debates do grupo de pesquisa: a relação entre o professor e um material didático, material esse que não é de autoria desse professor, mas que foi designado para sua atuação na disciplina. $\mathrm{O}$ docente se vê utilizando um material que nem sempre se adequa ao conteúdo que ele entende como relevante ou necessário e acaba inserindo materiais complementares.

A questão que dizia respeito às atividades propostas também é interessante por que mostra uma maior unanimidade de respostas. Há por parte dos respondentes uma atitude crítica que classifica as atividades propostas no material como pouco ou não suficientes. Como aparece no gráfico, somente uma pessoa respondeu como "suficientes" as atividades 
propostas no material didático, enquanto o restante dos respondentes assinalou uma defasagem nesse ponto.

O perfil que foi possível traçar da ação e utilidade de tais materiais no curso é de um material que não se mostra suficiente para o desenvolvimento da disciplina, nem sempre possui sugestões de outro material, com poucas propostas de atividades. Além disso, outras questões revelaram que o uso do material didático impresso pré-elaborado não seria feito da mesma forma se ele não fosse obrigatório. Se fosse de uso alternativo, reservado à decisão do professor de cada disciplina, o mesmo seria utilizado somente "em parte" pela maioria dos respondentes.

Os resultados dos questionários aplicados ao curso A vieram para confirmar o que já vinha sendo conjecturado para tal modelo: o uso de material impresso pré-elaborado é reconhecido pelos professores como insuficiente ou inadequado aos objetivos das disciplinas. Em reação, como apontam as respostas obtidas nos questionários, eles estão construindo caminhos alternativos, tanto para complementar o material quanto para desenvolver outras propostas paralelas.

No caso do curso B, destacamos, nos limites deste trabalho, duas questões por sua relevância. A primeira refere-se ao resultado obtido no questionário dirigido aos professores na pergunta que se refere ao possível uso de um material impresso pré-elaborado pelo curso. Nenhum dos professores respondeu que passaria a utilizar somente esse material préelaborado. O que ficou entendido é que eles adicionariam esse material como mais um recurso possível aos alunos, não deixando de produzi-los de forma singular, para cada disciplina, de acordo com as necessidades de cada disciplina.

Tabela 4 Se um material impresso pré-elaborado fosse disponibilizado à disciplina, você

\begin{tabular}{lcc}
\hline & Freqüência & Percentual \\
\hline $\begin{array}{l}\text { Passaria a utilizar somente o material impresso } \\
\text { pré-elaborado }\end{array}$ & - & - \\
$\begin{array}{l}\text { Adicionaria o material impresso pré-elaborado } \\
\text { aos demais materiais utilizados }\end{array}$ & 5 & 83,3 \\
$\begin{array}{l}\text { Não faria uso do material impresso pré- } \\
\text { elaborado }\end{array}$ & 1 & 16,7 \\
Total & & $100 \%$ \\
\hline
\end{tabular}

Fonte: Elaborado pelos Autores

Levando em consideração que não há o fundamento do uso de materiais impressos pré-elaborados, foi de interesse investigar quais materiais eram então utilizados pelos 
professores na construção da disciplina. Para isso, formulamos uma questão que possibilitasse marcar o uso ou não de vários materiais assim como a intensidade que os mesmos eram utilizados na disciplina. É possível perceber que não há somente um ou dois tipos de recursos didáticos utilizados na disciplina mas, de fato, uma adesão dos professores a diferentes possibilidades de materiais e recursos. Artigos científicos e video-aulas foram recursos assinalados por todos os professores, e videos/filmes e outros materiais da internet pela maioria dos docentes que responderam ao questionário. O livro foi o recurso menos assinalado.

Tabela 5 Que tipos de materiais pedagógicos são trabalhados no seu curso

\begin{tabular}{|l|c|c|c|c|c|c|c|c|}
\hline \multirow{2}{*}{} & \multicolumn{2}{|c|}{ Sim } & \multicolumn{2}{c|}{ Não } & \multicolumn{2}{c|}{ Não respondeu } & \multicolumn{2}{c|}{ Total } \\
\cline { 2 - 9 } & F & \% & F & F & \% & F & F & \% \\
\hline Livros & 2 & 33,4 & 4 & 2 & 33,4 & 4 & 6 & 100 \\
Capítulos de livros & 4 & 66,6 & 1 & 4 & 66,6 & 1 & 6 & 100 \\
Artigos & 6 & 100 & - & 6 & 100 & - & 6 & 100 \\
Video-aulas & 6 & 100 & - & 6 & 100 & - & 6 & 100 \\
Vídeos/filmes & 5 & 33,4 & 1 & 5 & 33,4 & 1 & 6 & 100 \\
Outros materiais da & 5 & 33,4 & 1 & 5 & 33,4 & 1 & 6 & 100 \\
internet & & & & & & & & \\
\hline
\end{tabular}

Fonte: Elaborado pelos Autores

\section{CONCLUSÕES}

As principais conclusões a que foi possível chegar, no decorrer das investigações acima rapidamente pontuadas, confirmaram, em grande medida, a importância do material didático na formatação das relações pedagógicas no interior dos cursos a distância. Assim, a maneira como ele é produzido expressa, desde seu início, a concepção de Educação a Distância dos agentes elaboradores do curso. Isto vale, no caso da UAB, principalmente na instância mais macro, das políticas públicas. A concepção dos cursos revelaria, portanto, certo caráter instrucionista e reprodutor da concepção vigente, no nível das decisões da gestão da própria UAB.

Contudo, o modo como o material é designado ao curso, não corresponde, necessariamente, ao modo como o material é utilizado nos cursos. Há tendência à autonomia nos modos de uso na medida em que o professor e/ou tutores são mais ou menos experientes, tanto com relação à prática pedagógica quanto ao domínio dos conteúdos. O modo como o material é usado, no interior dos cursos, configuraria e determinaria a relação entre seus principais atores - tutor e professor- e seus alunos. Determina, portanto, a própria organização 
do curso, a qualidade e frequência das interações pedagógicas, o lugar do aluno, como sujeito passivo ou construtor do seu próprio conhecimento.

Se o perfil do curso já está traçado pela instância governamental, que expõe a preferência no material didático, percebe-se que há um movimento no sentido de tentar contornar essa situação e dar qualidade para o curso de dentro para fora. Foi possível, portanto, perceber um interessante movimento contraditório dentro das determinações impostas à $\mathrm{EaD}$, como movimento que surge das próprias estruturas dadas. Os docentes tendem, de dentro do curso, como agentes internos, a desenvolver implementos de qualidade, optando por uma autoria e autonomia crescente, que passa a se assemelhar a uma concepção mais artesanal de ensino a distância.

Estas conclusões estão ainda sendo discutidas e exploradas, e deverão se tornar objeto de outras produções, considerando-se que o tema da pesquisa possui uma abrangência e atualidade que não permite que os resultados se concluam em apenas dois anos de estudo tempo de duração da pesquisa aqui condensada. É um campo que vem crescendo exponencialmente, em detrimento de pesquisas científicas da área, que não atingem número e intensidade satisfatórias e demonstram a necessidade de percorrer um grande caminho neste tema.

\section{REFERÊNCIAS BIBLIOGRÁFICAS}

BELLONI, Maria Luiza. Educação a distância. Campinas: Autores Associados, 2009.

BRASIL. Ministério da Educação. Secretaria de Educação a Distância. Referenciais de Qualidade para Educação Superior a Distância. 2007. Disponível em:

$<$ http://portal.mec.gov.br/seed/arquivos/pdf/legislacao/refead1.pdf $>$. Acesso em: 18 de novembro de 2011.

CASTELLS, Manuel. A sociedade em rede. São Paulo: Paz e Terra, 1999.

GIUSTA, Agnela da Silva. Educação a distância: contexto histórico e situação atual. Belo Horizonte: PUC Minas Virtual, 2003.

LITTO, Fredric Michael. O atual cenário internacional da EAD. In: FORMIGA, Manuel Carlos (Org). Educação a Distância: o estado da arte. São Paulo: Pearson Education do Brasil, 2009. P. 09-13

SANTOS, Boaventura de Souza. Pela mão de Alice: social e o político na transição pósmoderna São Paulo: Cortez, 1997. 
' BRASIL. Ministério da Educação. Secretaria de Educação a Distância. Referenciais de Qualidade para Educação Superior a Distância. 2007. Disponível em:

$<$ http://portal.mec.gov.br/seed/arquivos/pdf/legislacao/refead1.pdf $>$. Acesso em: 18 de novembro de 2011. 